\title{
Retraction Note to: Analysis of atmospheric climate characteristics in coastal areas and the influence of educational cognition on industrial structure changes
}

\author{
Jiajia Yu ${ }^{1} \cdot$ Qianrong Luo $^{1} \cdot$ Qian Gao $^{1}$
}

Published online: 13 December 2021

(c) Saudi Society for Geosciences 2021

Retraction Note to: Arabian Journal of Geosciences (2021) 14: 1386 https://doi.org/10.1007/s12517-021-07758-0

The Editor-in-Chief and the Publisher have retracted this article because the content of this article is nonsensical. The peer review process was not carried out in accordance with the Publisher's peer review policy. The authors have not responded to correspondence regarding this retraction.

The original article can be found online at https://doi.org/10.1007/ s12517-021-07758-0.

Qian Gao

hyqdragon6@163.com

1 Chongqing Jianzhu College Construction Management and Real Estate, Chongqing 400072, China 